\title{
Retardation Mechanism Analysis of Core Layer Material of Engineered Material Arresting System
}

\author{
Yumei Sun ${ }^{1, a}$, HongbinYu ${ }^{1, b}$, \\ ${ }^{1}$ School of Mechanical Engineering, Tianjin Polytechnic University, Tianjin, 300387, China. \\ aguimei2901@163.com, bhongbinyu@aliyun.com
}

Keywords: EMAS, Foam concrete material, Aircraft, Emergency.

\begin{abstract}
According to the statistical of aviation safety, arresting system must be installed on the runway with effective way, in order to maximize reduce the risk of overshot the runway and the damage to plane carrying personnel loss rate. ESCO companies began to study Engineered Material Arresting System(EMAS) in the United States from 1986. It is a new type of runway arresting system which is made up of highly broken foam concrete material and laid in the end of the runway for aircraft emergency stops. For safety area that can't achieve ICAO technical requirements provides a feasible solution at the airport. EMAS principle is the use of the rectangle of foam concrete pavement materials in the runway safety area, if the plane overshot the runway, it will rushed into the foam concrete material, thus can absorb the impact energy of the aircraft, the aircraft slowed last within the scope of the safety distance to stop. After 30 years of development, the EMAS has been successfully installed all over the world produced at USA. Accordingly, domestic EMAS has also been successfully produced and installed in China.
\end{abstract}

\section{Introduction}

Core layer foam concrete material of EMAS was characterized as large amounts of internal pores which would disappeared under pressure wave to eliminate the porosity, then forming a dense material, The core layer of foam concrete material density process of EMAS can be divided into several stages: Elastic deformation occurs at the hole wall, and some of the impact energy was transferred into elastic performance at the first stage. At the same time, the air gap was adiabatic compression and absorb energy; Then, the plastic collapse or brittle broken of hole wall appeared. A part of the impact energy was transferred into plastic performance, air-gap adiabatic compression process was nearly over; Thereafter, it have been gradually compacted until form a dense material. Meanwhile, its performance of EMAS core layer material would change under the condition of freezing and thawing, will happen very big change. EMAS core layer foam concrete material after being frozen, the holding strength capacity would decrease. The crack forming work under pressure in the freeze-thaw environment will reduce remarkably energy absorption in the process of block.

\section{Preparation of EMAS Core Layer Material}

EMAS core layer of foam concrete was used in the experiment, its configuration ratio was shown at the table 1.

Test pieces was prepared by the Chemical foaming method. Hydrogen peroxide with good properties of environmental protection was chosen as the foaming agent as the chemical reactions were easily to process under the alkaline conditions creating by on the dissolution of silicate cement concrete into water. When the $\mathrm{pH}$ of slurry formed by mixing the cement and water by stirring was 10 , oxygen was produced sufficiently by hydrogen peroxide and independent bubble nucleation was formed. when the value of internal pressure is higher than the sum of slurry bubble and the resistance, air bubbles in the slurry inflated until pressure reach equilibrium, then independent closely holes were formed. Gas diffuse from a smaller high pressure cavity to larger low pressure one until the smaller shrinkage hole was consumed by larger cavity. With the increasing of cavity pressure reached equilibrium between the cavity. Then distribution state of test piece of cavity was 
formed with the gradually hardening of slurry.

Table 1 Configuration ratio of EMAS core layer material

\begin{tabular}{cccccc}
\hline $\begin{array}{c}\text { Water } \\
\text { cement } \\
\text { ratio }\end{array}$ & $\begin{array}{c}\text { Ordinary } \\
\text { Portland } \\
\text { cement } \\
62.5(\mathrm{~g})\end{array}$ & $\begin{array}{c}\text { water } \\
(\mathrm{g})\end{array}$ & $\begin{array}{c}\text { Foaming agent } \\
(\mathrm{g})\end{array}$ & $\begin{array}{c}\text { Steady bubble } \\
\text { reagent } \\
(407 / \mathrm{GT} / \mathrm{Y})\end{array}$ & $\begin{array}{c}\text { Dry density after } \\
\text { curing } \\
(\mathrm{g} / \mathrm{mm} 3)\end{array}$ \\
\hline 0.779 & 1000 & 700 & 80 & $7 \mathrm{~g} / 7 \mathrm{~g} / 10 \mathrm{~g}$ & $243 \pm 10$ \\
0.784 & 1000 & 700 & 80 & $7 \mathrm{~g} / 7 \mathrm{~g} / 15 \mathrm{~g}$ & $245 \pm 10$ \\
0.774 & 1000 & 750 & 80 & $9 \mathrm{~g} / 9 \mathrm{~g} / 8 \mathrm{~g}$ & $224 \pm 10$ \\
0.823 & 800 & 600 & 64 & $6 \mathrm{~g} / 6 \mathrm{~g} / 8 \mathrm{~g}$ & $230 \pm 10$ \\
0.903 & 800 & 650 & 75 & $7 \mathrm{~g} / 7 \mathrm{~g} / 10 \mathrm{~g}$ & $180 \pm 10$ \\
0.909 & 800 & 650 & 80 & $7 \mathrm{~g} / 7 \mathrm{~g} / 10 \mathrm{~g}$ & $180 \pm 10$ \\
0.906 & 800 & 650 & 80 & $8 \mathrm{~g} / 8 \mathrm{~g} / 10 \mathrm{~g}$ & $180 \pm 10$ \\
0.93 & 800 & 650 & 100 & $8 \mathrm{~g} / 8 \mathrm{~g} / 10 \mathrm{~g}$ & $140 \pm 10$ \\
\hline
\end{tabular}

\section{Absorption Ability of the Core Material of EMAS}

There are three stages of compressive stress - strain curve of Foam concrete[1], namely the linear elastic, densification and yield platform paragraphs. Period of linear elastic is short, curvature of cell walls of bubble cavity changed in this stage. At the stage of yield platform, with the increase of strain of cavity wall, foam concrete began to yield, local buckling or cracks. Because of the conditions such as temperature, stirring speed, the same piece of different parts of the test block cavity size and the shape is not completely consistent, the cavity wall in the compression process will have different forms of damage during the preparation process. After the yield platform, cavity was nearly broken, leading to the further compaction and densification of foam concrete. To improve foam concrete intensity, hardness, appear similar to the real concrete hardening phenomenon, in this phase stress value was significantly promoted[2], the slope of stress - strain curve increase remarkably with the increasing of elastic modulus $\left(E_{s}\right)$ of ordinary silicate cement.


Fig. 1 The compression function of the foam concrete curve

Endergonic process of EMAS core layer foam concrete mainly occurs in the yield platform. the impact of the external load energy into a bubble cavity of yield, collapse, crushing, cavity wall friction between the consumption of energy in the form in the compression process. Based on the energy absorption amount of effective volume, unit energy absorption and energy absorption efficiency to evaluate energy absorption ability of foam concrete. Energy absorption efficiency ( $\eta$ ) is defined as the actual absorption energy and the ratio of the ideal energy absorption value, then energy absorption value computation formula is shown at below:

$$
\begin{aligned}
& W=\int_{0}^{\delta_{D}} F(\delta) d \delta \\
& W_{V}=\int_{0}^{\varepsilon_{D}} \sigma(\varepsilon) d \varepsilon
\end{aligned}
$$


$\eta=\frac{\int_{0}^{a_{D}} \sigma(s) d s}{\sigma_{\max \sigma_{D}}}=\frac{W_{Y}}{\sigma_{\operatorname{mex} \varepsilon_{D}}}$

Type of $\mathrm{W}$ - energy absorption quantity effectively;

$F(B)$ - The compression load;

$\delta_{2}$-Densification stage starting point displacement;

$\mathbf{W}_{\mathrm{v}}$-Energy absorption per unit volume;

$\sigma(g)$ _Compressive stress;

$\sigma_{\max }$-Before reach $\mathscr{E}_{D}$ the maximum compression stress.

For application materials, the properties and not only by the material energy absorption efficiency of calculation of energy absorption per unit volume or measured, in the process of compression process or impact, the peak stress of the material is also an important evaluation parameter. Foam concrete used in EMAS core layer should have a certain hardness and high impact resistant performance on smaller speed range.

\section{Research of Energy Absorption Mechanisms of EMAS Core Layer Material}

New type of porous materials are mainly used to convert kinetic energy into some other kinds of energy capabilities for protection. using its cell wall compression bending and buckling collapse of to absorb the impact of mechanical energy. When foam concrete block are compressed, linear elastic deformation not occurred firstly; Then buckling cavity was produced, leading to non-linear elastic stage; Finally, cavity collapsed completely. As the pore surface and hole edge pressed together, the stress rose sharply. For us, to observe the foam concrete, gradual compression will lead to a compression buckling platform, end the platform in the material completely[3].

In the portable were observed under magnifying glass $100 \mathrm{~mm} * 100 \mathrm{~mm} * 100 \mathrm{~mm}$ block compression test of microstructure, the compression process is shown in the follow figure.

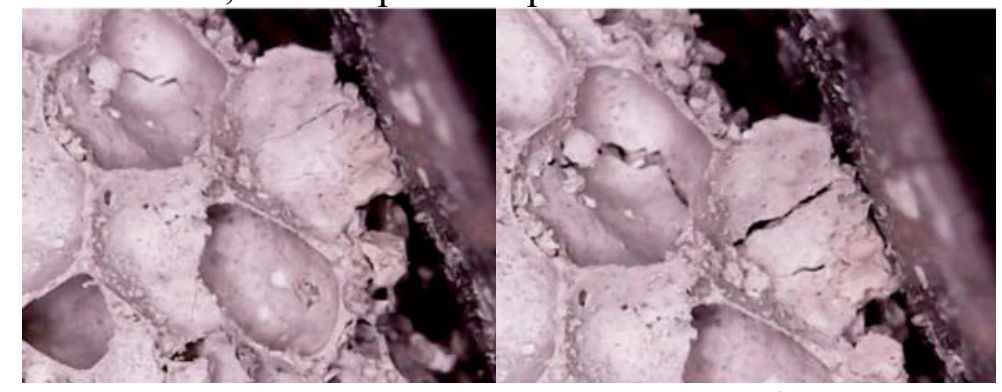

a)

b)

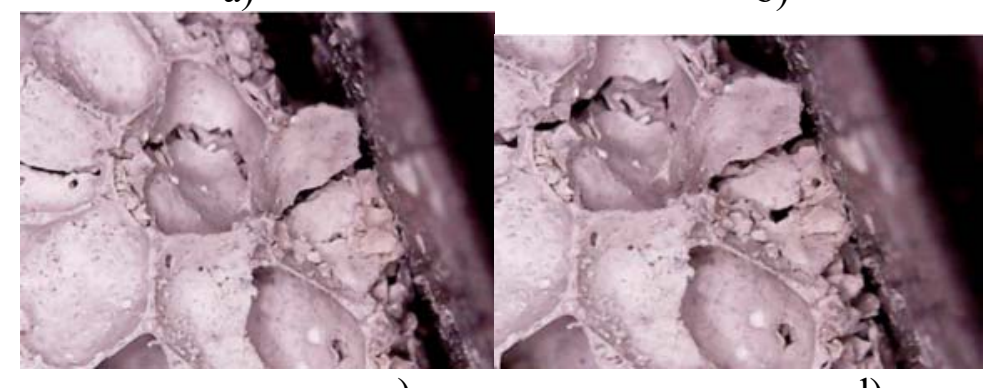

c)

d)

Fig.2 Under the magnifying glass to observe the breakage of the obturator cavity under the effect of pressure change

Fig.2 a) Cavity compressed contact surface contact, cavity micro cracks appear, the curve into the bearing capacity of the performance for elastic force; Fig.2 b) Several cavity has a significant crack, as the compression contact press, viscous force, friction force between the fracture cavity wall as the main bearing capacity; Fig.2 c) $\sim$ d)There are multiple cracks, cracks a single cavity between the cavity wall without focus away from the main body, or falling into a cavity or falling to the ground, fall into the cavity of the cavity wall, because of its still has the certain strength, in the 
subsequent compression process will be repeated the process of Fig.2 a) c) mechanism and the energy absorption effect until they are pressed into foam.

Linear elastic was controlled by bending of hole wall, for a closed cavity foam concrete block, is controlled by the pore surface extension, when compression loading, the yield platform and the cavity wall of brittle fracture and cavity wall materials associated shape collapse[4], the test block as the pressure loss of the brittleness. When the cavity collapse of almost no security, when the relative surface contact, further compression strain is a solid itself, it is concluded that the stress burgeoning area.
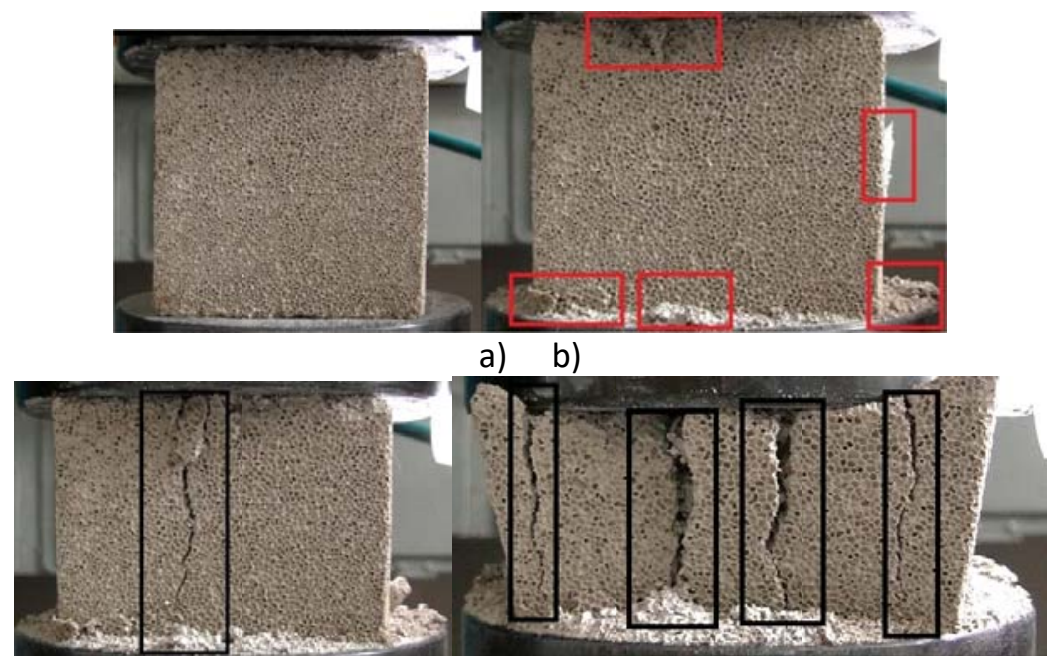

c)

d)

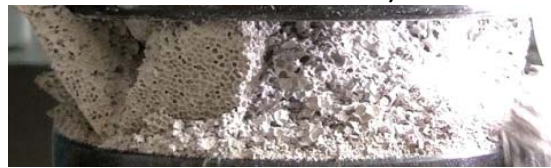

e)

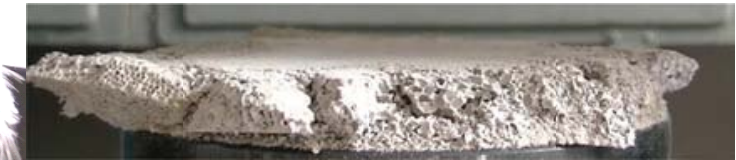

f)

Fig.3 A physical change in the core layer material of EMAS compression loads

Fig. 3 a)Not load; Fig.3 b)Online elastic area load bending of hole wall; Fig. 3 c)In the linear elastic section buckling loads of hole wall; Fig. 3 d)When unloading elastic recovery; Fig.3 e)Elastic and plastic bubble; Fig. 3 f)Elastic and plastic foam.

\section{EMAS Core Material Performance Changes Before and After Freezing and Thawing}

It was soaked in water block in $-20^{\circ} \mathrm{C}$ to six hours, then the environment of freeze thawing in $50^{\circ} \mathrm{C}[5]$. After the freeze-thaw cycle 10 times the magnification microscope block surface, clear block surface has cracks. As shown in the figure 4.

As we can see, the size and width of cracks are different. It could be concluded that it will have different levels of ability to under decreasing pressure[6]; Due to the use of tissue properties materials is a closed cavity energy absorption ability, these cracks will also be cut the block in the process of energy absorption effect[7]. Flooding block and not block freeze-thaw cycle immersion test comparison: and not flooding the freeze-thaw cycle of crack width, length, soaking the freeze-thaw cycle of crack are larger, and the range of crack is bigger[8]. 

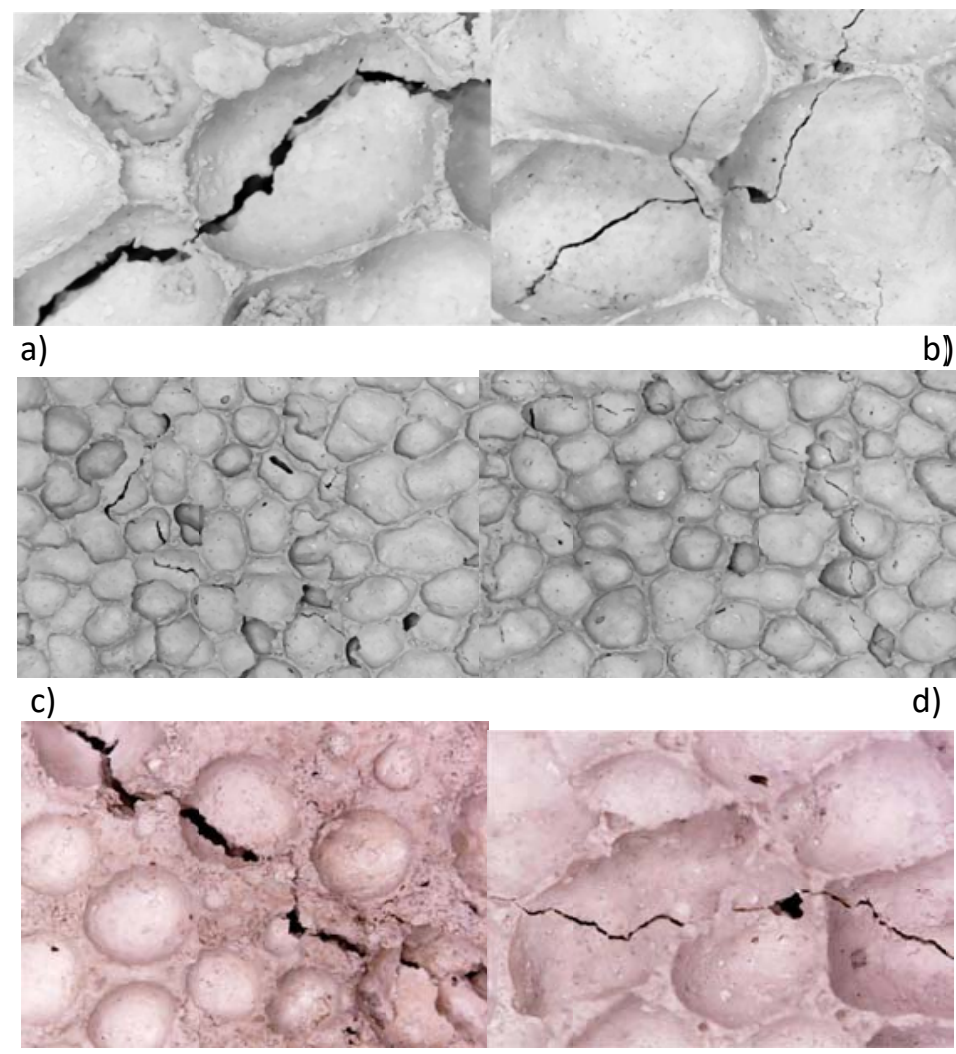

e)

f)

Fig.4 Freeze-thaw environment obturator cavity in the breakage of the pressure change

\section{Conclusions}

Runway arresting system is the core part of the arresting material, the current domestic research of block with main material of polymer porous materials, foam concrete materials. EMAS core layer was used for foam concrete material, in order to achieve autonomous localization of EMAS, grasp its core technology, puts forward the EMAS core layer under the action of wheel failure pattern test. The test main content of EMAS core layer under the action of aircraft wheel failure pattern and the energy absorption mechanism of scientific research, through the study of EMAS morphology of fractured core unit, establish its under different speeds and under the action of an aircraft wheel block performance model, developed with independent intellectual property rights of EMAS block distance calculation software, as in the actual production process of different density and intensity of EMAS unit optimization analysis has been made to the shop at the airport, for domestic EMAS shop is applied to build a theoretical foundation.

\section{Acknowledgements}

The work described in this paper is financially supported by the Civil Aviation Joint Research Foundation and by the National Natural Science Foundation of China under grant NO. U1333129.

\section{References}

[1] Xuezhou Yan, Qianfeng Yao. Foam concrete mechanics performance test research. Industrial building Vol. 37(2007), p. 962-964.

[2] Yaoqing Xiong, Qianfeng Yao. Light porous concrete compressive stress - strain curve experiment research . Sichuan construction science research .Vol. 36(2010) No. 02, p.228-232.

[3] Just A, Middendorf B. Microstructure of high-strength foam concrete[J].Materials Characterization. Vol. 60(2009), No. 07, p. 741-748. 
[4] Kunhanandan Nambiar E K, Ramamurthy K. Air-void characterisation of foam concrete[J]. Cement and concrete Research. Vol. 37(2007), No. 02, p. 221-230.

[5] Huaishuai Shang, Yupu Song. Behavior of air-entrained concrete under the compression with constant confined stress after freeze-thaw cycles[J]Cement \& Concrete Composites.30(2008) $854-860.0$

[6] Jinxiang Hong, Changwen Liao. The influence of the freeze-thaw damage of concrete fatigue performance. Journal of civil engineering .Vol. 45 (2012) No. 06, p. 83-89.

[7] Xingben Shan. Foam concrete frost resistance test research. Building technology at low temperature . (2015) No. 01, p. 26-28.

[8] Indu Siva Ranjani G, Ramamurthy K. Behaviour of foam concrete under sulphate environments[J].Cement and Concrete Composites, Vol. 34 (2012) No. 07, p. 825-834. 